\title{
Erratum to: Cerebral Near-Infrared Spectroscopy Correlates to Vital Parameters During Cardiopulmonary Bypass Surgery in Children
}

\author{
Jan Menke · Gerhard Möller
}

Published online: 10 June 2014

(C) Springer Science+Business Media New York 2014

\section{Erratum to: Pediatr Cardiol (2014) 35:155-163 \\ DOI 10.1007/s00246-013-0754-9}

The study outlined in our article [1] included data collected in 1996-1997, but analyzed in 2012-2013. The institutional approval referred to in this article was through the university hospital's Ethics Committee on Human Research at the University Hospital of Muenster, Germany, where the study data were collected in patients of that hospital. Novel aspects of this study referred to the dense data sampling and the application of a random-effects models for analysis. This analysis and the manuscript preparations were done by the authors through private non- institutional research in 2012/2013. This study was not performed at the University Medical Center Goettingen, where the first author is employed. The corrected address for correspondence now is the private address of the first author (Jan Menke).

\section{Reference}

1. Menke J, Möller G (2014) Cerebral near-infrared spectroscopy correlates to vital parameters during cardiopulmonary bypass surgery in children. Pediatr Cardiol 35:155-163
The online version of the original article can be found under doi:10. 1007/s00246-013-0754-9.

\section{J. Menke $(\bowtie)$}

Am Hachweg 1, 37083 Goettingen, Germany

e-mail: Menke-J@T-Online.de

G. Möller

Department of Pediatrics, University Hospital Goettingen,

Robert-Koch-Strasse 40, 37075 Goettingen, Germany 